\title{
Xeroderma Pigmentosum with Simultaneous Cutaneous and Ocular Squamous Cell Carcinoma
}

\author{
Raden Mohamad Rendy Ariezal Effendi (D), Azmi Fadhlih (D), Inne Arline Diana (D), \\ Srie Prihianti Gondokaryono (D), Reiva Farah Dwiyana (D) \\ Department of Dermatology and Venereology, Faculty of Medicine, Universitas Padjadjaran - Dr. Hasan Sadikin Hospital, Bandung, Indonesia
}

Correspondence: Raden Mohamad Rendy Ariezal Effendi, Department of Dermatology and Venereology, Faculty of Medicine, Universitas Padjadjaran Dr. Hasan Sadikin Hospital, Bandung, Indonesia, Email rendy.ariezal.effendi@unpad.ac.id

\begin{abstract}
Xeroderma pigmentosum (XP) is a rare autosomal recessive disease that disrupts deoxyribonucleic acid (DNA) repair due to ultraviolet (UV) radiation. XP is characterized by extreme sensitivity to sunlight, photophobia, cutaneous lesions in the form of freckle-like hyperpigmented macules, and neoplasia on the skin surface. Malignancy is a common complication found in areas exposed to UV light. Squamous cell carcinomas (SCC) is the most common malignancy seen in patients with XP. This report illustrates a case of XP in a six-yearold girl with cutaneous and ocular SCC. The diagnosis of XP was established based on the patient's history and the presence of typical clinical manifestations. Dermoscopy and histopathology examinations confirmed the presence of SCC on the face and eyes. The management of XP patients includes early diagnosis, lifelong UV protection, and early detection of cutaneous malignancy. Early detection and appropriate management are very important in preventing the occurrence of malignancy.
\end{abstract}

Keywords: dermoscopy, ocular carcinoma, squamous cell carcinoma, xeroderma pigmentosum

\section{Introduction}

Xeroderma pigmentosum (XP) is a rare autosomal recessive disease characterized by extreme sensitivity to ultraviolet (UV) light, ${ }^{1,2}$ photophobia, cutaneous lesions in the form of freckle-like hyperpigmented macules, and neoplasia on the skin surface. ${ }^{2}$ This condition occurs due to an abnormality of nucleotide excision repair (NER) caused by a mutation to any of eight genes (XPA-G and XPV). ${ }^{2,3}$ The repair defect of XP cells is identified by showing that XP cells have decreased rates of unscheduled DNA synthesis. ${ }^{2}$ This condition results in pigmentation changes and the formation of carcinogenic photoproducts, which leads to skin cancers. ${ }^{2,4}$

The prevalence of XP is about 1: 250,000 worldwide, ${ }^{5}$ and this disease is known as one of the predisposing factors for cutaneous malignancy. The risk of cutaneous malignancy increases 10,000-fold in areas exposed to UV light. ${ }^{6}$ Basal cell carcinoma (BCC) and squamous cell carcinoma (SCC) are the most common malignancies, whereas cutaneous melanoma is less common. ${ }^{7}$ Ocular manifestations are one of the main and early features of XP that occurs in $40-80 \%$ of all XP cases, ${ }^{8}$ However, ocular surface carcinoma is very rare, about only $2 \%$ of all XP cases with ocular manifestation. ${ }^{9}$

Management of patients with XP involves lifetime protection against exposure to UV radiation, as well as early detection and treatment of neoplasms. ${ }^{10}$ Regular visits to a dermatologist should be taken to remove any pre-cancerous lesion as early as possible. ${ }^{2}$ Skin neoplasms should be treated by a procedure such as electrodesiccation and curettage, surgical excision, or Mohs surgery. ${ }^{1}$ XP decreases the quality of life, especially in school-aged children in tropical countries. This report presents a rare case of XP with simultaneous cutaneous and ocular SCC as complications with an emphasis on preventing malignancy on XP management, which could increase the life expectancy of the patient.

\section{Case}

A 6-year-old girl was brought by her parents to the Pediatric Dermatology Clinic, with hyperpigmented macules on the skin areas exposed to sunlight accompanied by painful nodules on her face. The complaint first appeared when she was 2 
years old. One year prior to the visit, the nodules on the left upper forehead appeared to have enlarged. The patient also complained of reddish eyes that were often scratched, with photophobia, as well as blurry vision. Since 2 weeks before the visit, the nodules on her upper forehead were rapidly increasing in size. She was born to non-consanguineous parents and no similar complaints were experienced by family members. Now, she no longer goes to school because of her condition. Physical examination revealed nodules on both eyes. Dermatological examination found multiple lesions of hyperpigmented and hypopigmented macules, with scales in sun-exposed skin areas (Figure 1). Multiple nodules and ulcers were observed on the forehead and the edges of the upper lip. Dermoscopy examination performed on nodules and ulcer showed a visible white circle (Figure 2A) and white structureless (Figure 2B), which are indicative of SCC. Extirpation biopsies were done on those lesions and histopathological examination revealed features of SCC, specifically a layered and flat epithelium turning into a tumor mass consisting of round, oval, and polygonal hyperplastic cells. The cellular nuclei were pleomorphic, hyperchromatic, some vesicular with clear nuclei, and there were signs of increased mitotic activities. Formation of keratin mass was also seen. Fibrocollagen connective tissue stroma appeared swollen with infiltration of lymphocytic inflammatory cells along with focal bleeding (Figure 2C). Consultations to the pediatric and the otorhinolaryngology-head and neck Departments found no neurological deficit or hearing loss. The nodules in both eyes were extirpated by an ophthalmologist and the histopathological examination also revealed features of SCC (Figure 3). Based on the examinations, the patient was diagnosed with XP with bilateral ocular surface SCC. She was then instructed to implement full UV protection by wearing fully covered clothing and sunglasses over a full-body application of sunscreen with SPF $45 \mathrm{PA}++$. In addition, sunscreen should be reapplied every 2 hours especially in areas not protected by clothes. The patient was advised to attend regular visits every 3-6 months to the dermatologist and ophthalmologist to detect the presence of new malignancies, both cutaneous and ocular.

\section{Discussion}

Almost one-half of XP patients tan normally without excessive burning. Meanwhile, severe sunburn with blisters may develop after very short sun exposure for another patient, even through window glass. Within 24 hours, the severe skin burning reaches a maximum, and then resolves for the next 4-6 days, lasting longer than in normal healthy individuals. In later stages of infancy, pigmentary changes in sun-exposed skin develop. Poikiloderma becomes apparent, including telangiectasia and atrophic hyper- as well hypopigmentation. In the next stage, usually in early childhood, the first skin cancers appear that include such as BCC, SCC, and cutaneous melanoma. ${ }^{2}$ In this patient, the cutaneous lesion first

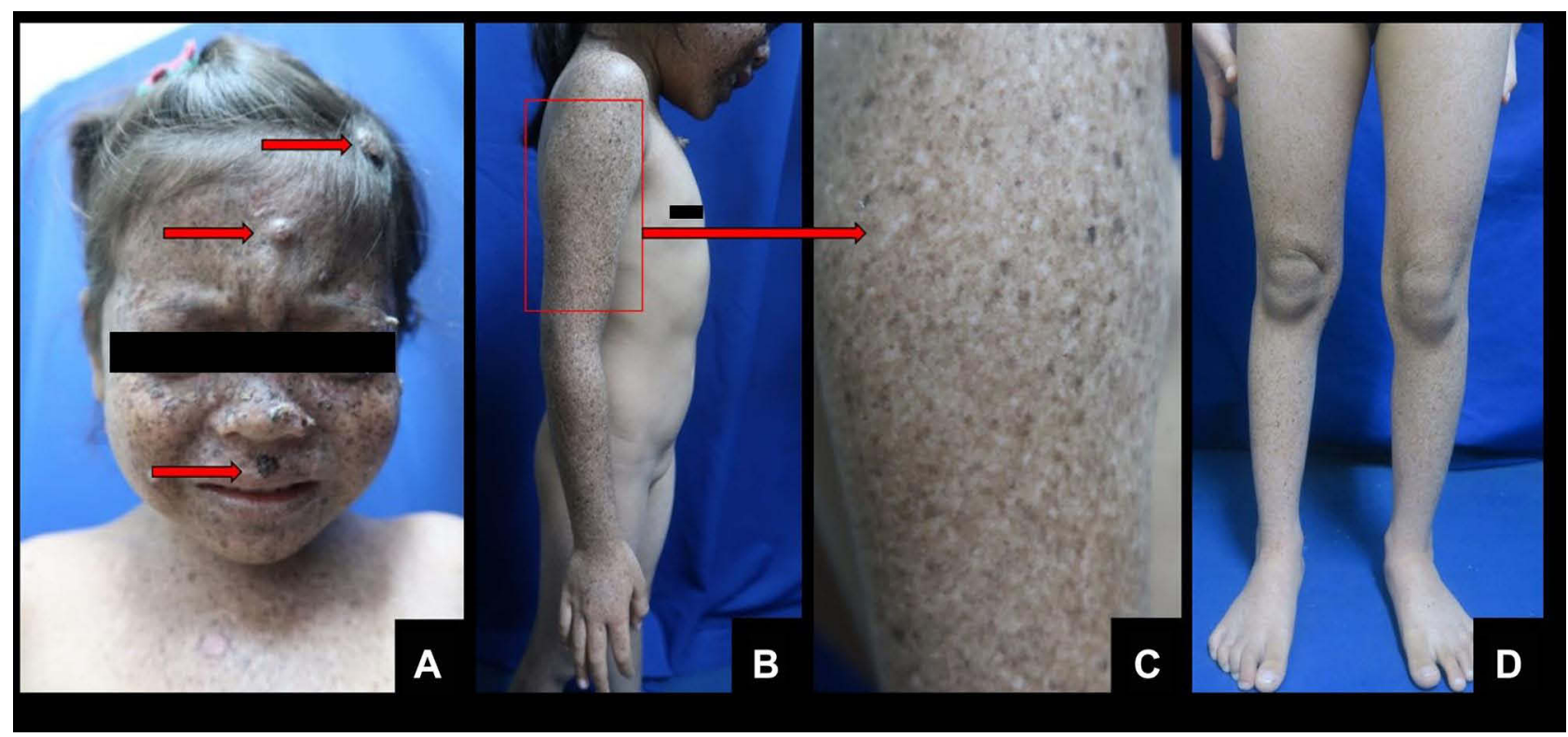

Figure I Hyperpigmented macules, hypopigmented macules, and scales on the face, chest, back, and both extremities (A-D). On the forehead and upper lip edges, we could see multiple lesions such as nodules, ulcers, and squama (A). 


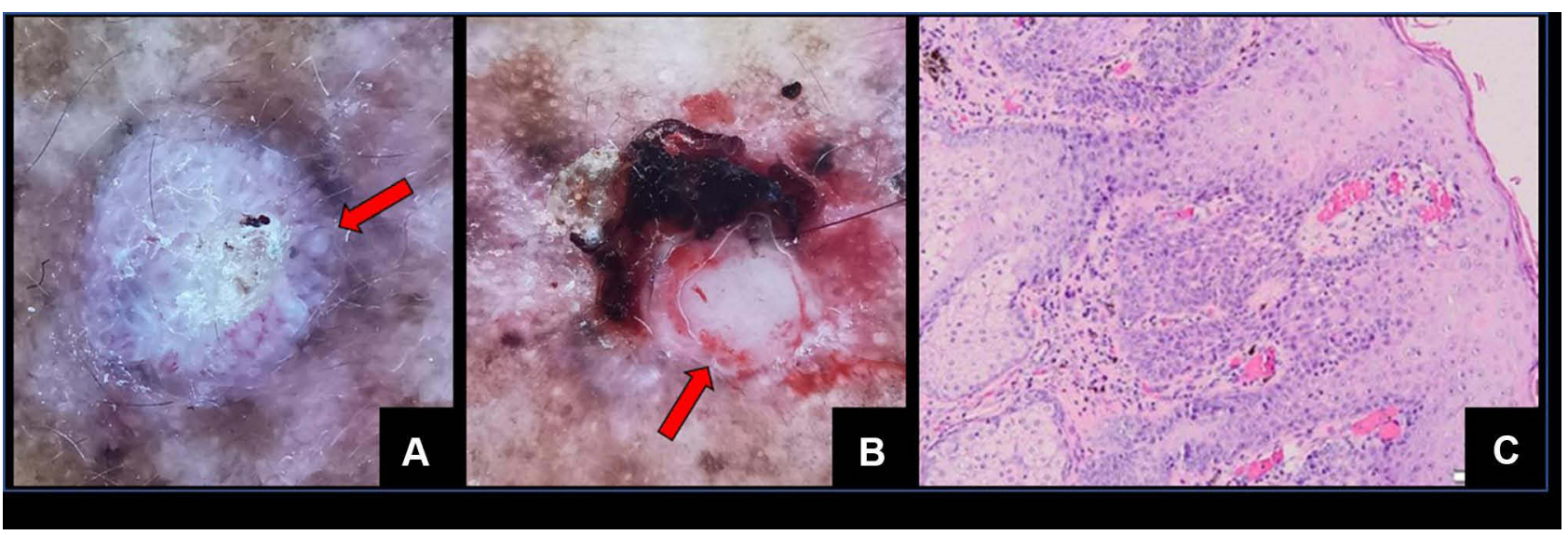

Figure 2 (A) Dermoscopy examination performed on nodules and ulcer showed a visible white circle (B) white structureless area (C), and histopathology examination revealed polymorphic and atypical cells with an increase of mitotic nuclei.

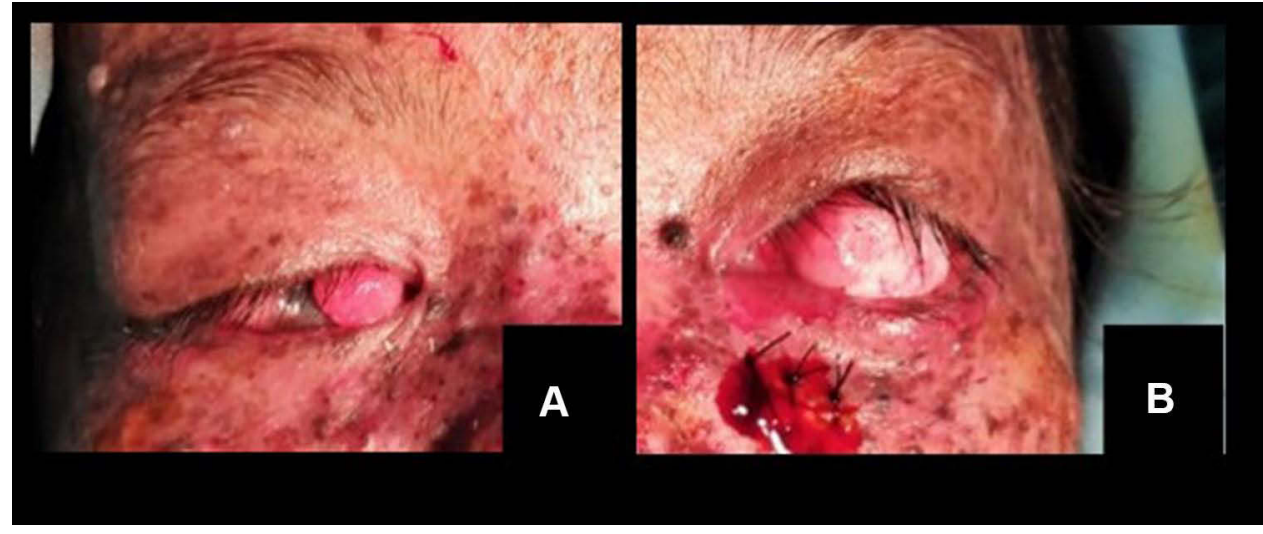

Figure 3 (A) Nodules in the right eye, (B) nodules in the left eye prior to the extirpation biopsy procedure.

appeared at the age of 2 years old in the form of hyperpigmented macules in areas exposed to sunlight. Malignant cutaneous tumors were found to develop when the patient was 5 years old.

The emergence of epithelial neoplasms, severe ocular involvement, and progressive neurological degeneration are some of the clinical manifestations of XP. ${ }^{10}$ One of the most common malignancies following XP is SCC. ${ }^{7}$ To date, all of $\mathrm{XP}$ cases in our hospital came with some form of skin cancer, whether it is BCC or SCC. Dermoscopy is a non-invasive technique for diagnosing cutaneous lesions and differentiating benign and malignant lesions. The dermoscopy criteria for SCC include the presence of keratin, blood spots, white circles, white structureless areas, hairpin vessels, linear-irregular vessels, perivascular white halos, and ulcerations. ${ }^{11}$ Dermoscopy examination of all nodules, in this case, indicated the presence of SCC, with a white circle in the middle forehead lesion, as well as a white structureless area and in the upper left forehead and upper lip lesions.

On histopathological examination, SCC usually has a variable proportion of squamous cells that appear normal and atypical, and are characterized by an increase in mitosis, aberration of mitotic numbers, nuclear hyperchromasia, and loss of intercellular bridges. ${ }^{12}$ Histopathological examination results from the extirpation biopsies of nodules on the face illustrated the presence of SCC, as indicated by the presence of polymorphic and atypical cells as well as increased mitotic nuclei.

XP could be found in all races and genders. Moreover, the incidence is genetically determined and increases with consanguinity. ${ }^{2}$ The only one case of XP in Indonesia was reported by Yuniati et al. ${ }^{4}$ They reported a novel pathogenic variant of XPC, c1941T>A that was found in the second family. ${ }^{4}$ To date, there has not been any specific XP gene mutation research in Indonesia yet. Gene mutation testing and family counseling could help in early detection and 
determine various clinical manifestations. ${ }^{7} \mathrm{New}$ advances in molecular biology strategy, such as next-generation sequencing (NGS) used by Yuniati et al, could lead to early diagnosis, but they are still scarce. ${ }^{4}$ In this case, gene mutation testing has not been carried out, due to its unavailability in Indonesia and needs to be sent abroad, hence it is very costly.

Following continuous exposure to UV light, individuals with XP can show signs of conjunctival melanosis, cataracts, atrophy, entropion or ectropion, trichiasis, and loss of the lower eyelid. ${ }^{10}$ Ocular surface squamous neoplasia (OSSN) is a general term used for all premalignant epithelial lesions and malignancies occurring in the conjunctiva and cornea. This is most commonly found in the interpalpebral area near the limbus. ${ }^{5}$ Bilateral OSSN is rare for an unknown reason with a synchronous and metachronous presentation. The prevalence of bilateral OSSN is higher in immunocompromised patients and XP patients. ${ }^{13}$ Based on the histopathological examination results following the extirpation biopsy on the nodules on both eyes by an ophthalmologist, the patient was diagnosed with bilateral ocular surface SCC.

The management of patients with XP consists of lifetime protection from UV exposure as well as the early detection and treatment of neoplasms, oral medication with isotretinoin or vitamin $\mathrm{D}$, hearing aids for some with hearing loss, frequent eye examination by ophthalmologists, pre-cancerous lesion examination by dermatologists, and psychosocial issues solving. ${ }^{210}$ Psychosocial issues should be taken are such as social isolation from school friends, career prospects, and many more to prevent further impact on patient self-confidence. ${ }^{2}$ In this case, the patient no longer goes to school and rarely plays with friends because of her condition.

Removing neoplasm could be done by electrodesiccation and curettage, surgical excision, or Mohs surgery. ${ }^{1}$ The aim of UV exposure protection is to reduce the amount of UV radiation that reaches the tissues in XP patients. ${ }^{14}$ Patients must minimize UV exposure and use sunscreen with at least SPF 30 every day. ${ }^{10}$ The first application in the morning must be to all areas of the skin. During the day, sunscreen must be reapplied every 2-3 hours to the face, neck, ears, and hands, as well as other areas that are not constantly covered by clothing. ${ }^{14}$ In this case, the patient was prescribed a broad-spectrum sunscreen (SPF 45 and PA++) for daily use with specific instructions on how to apply and reapply. She was also instructed to use full covering clothes and sun-protective sunglasses. The patient was advised to attend routine visits to the dermatologist and ophthalmologist for early detection of new malignancies, both on the cutaneous and ocular. Implementing strict UV protection in Indonesia, a country that has abundant sun rays all year long is a challenge in itself.

Extirpation biopsies to neoplasms were done on both eyes and skin. The histopathological examination from both locations revealed features of SCC. Although most SCC is curable, $14 \%$ of them can metastasize and $40 \%$ of them eventually lead to death. ${ }^{15}$ The development of skin cancer, progressive neurological symptoms, and resulting complications drastically reduce the life expectancy of XP patients. ${ }^{2}$ Therefore, early detection and appropriate management of XP patients are very important to prevent undesirable outcomes. To realize this, it is necessary to have collaboration among patients, families, and communities, regarding UV safe living practices to increase the patients' quality of life. The authors recommend creating an XP family support group in Indonesia that has not been established yet.

\section{Conclusion}

Xeroderma pigmentosum is a rare autosomal recessive disease. Two of the most common malignancies in XP patients are BCC and SCC. Ocular manifestations can be the main presenting component and initial feature of XP disease. Management of patients with XP involves lifetime protection against UV radiation exposure, as well as early detection and treatment of neoplasms. Early detection and appropriate treatment can prevent the onset of malignancy, improve the patients' quality of life, and increase life expectancy.

\section{Ethical Statement}

The publications of images were included in the parents' consent for publication of the case.

Institutional approval to publish the case details has been obtained.

\section{Consent Statement}

The authors certify that they have obtained all appropriate patient consent forms. The parents of the patient signed a consent form for the publication of the case details and images. 


\section{Acknowledgments}

The authors would like to thank the staff of the Department of Dermatology and Venereology, Faculty of Medicine, Universitas Padjadjaran-Dr. Hasan Sadikin General Hospital, Bandung, West Java, Indonesia.

\section{Funding}

There is no funding to report.

\section{Disclosure}

The authors report no conflicts of interest in this work.

\section{References}

1. Runger TM, DJ, Kraemer KH. Hereditary disorders of genome instability and DNA repair. In: Kang S, Amagai M, Gilchrest BA, et al., editors. Fitzpatrick's Dermatology. 9th ed. New York: McGraw Hill; 2019:2347-2354.

2. Lehmann AR, McGibbon D, Stefanini M. Xeroderma pigmentosum. Orphanet J Rare Dis. 2011;6(1):1-6. doi:10.1186/1750-1172-6-70

3. Schubert S, Oranje ES. Xeroderma pigmentosum and related disease. In: Hoeger P, Yan A, editors. Harper's Textbook of Pediatric Dermatology. 4th ed. Willey Blackwell; 2020:1743-1768.

4. Yuniati R, Sihombing NRB, Nauphar D, et al. Clinical manifestation and genetic analysis of familial rare disease genodermatosis xeroderma pigmentosum. Intractable Rare Dis Res. 2021;2020:3143.

5. Kalamkar C, Radke N, Mukherjee A, Radke S. Xeroderma pigmentosum with bilateral ocular surface squamous neoplasia and review of the literature. Case Rep. 2016;2016:bcr2016215364.

6. Emir S, Hacısalihoğlu Ş, Özyörük D, Kaçar D, Erdem A, Karakuş E. Squamous cell carcinoma associated with Xeroderma pigmentosum: an unusual presentation with a tremendously huge mass over the face and paraneoplastic hypercalcemia-hyperleukocytosis. Turk J Pediatr. 2017;59 (6):711-714. doi:10.24953/turkjped.2017.06.017

7. Ribeiro MG, Zunta GL, Santos JS, Moraes AM, Lima CSP, Ortega MM. Clinical features related to xeroderma pigmentosum in a Brazilian patient diagnosed at advanced age. Appl Clin Genet. 2018;11:89. doi:10.2147/TACG.S155083

8. Naik SM, Shenoy AM, Nanjundappa A, et al. Cutaneous malignancies in xeroderma pigmentosum: earlier management improves survival. Indian $J$ Otolaryngol Head Neck Surg. 2013;65(2):162-167. doi:10.1007/s12070-012-0614-6

9. Lim R, Sethi M, Morley AM. Ophthalmic manifestations of xeroderma pigmentosum: a perspective from the United Kingdom. Ophthalmology. 2017;124(11):1652-1661. doi:10.1016/j.ophtha.2017.04.031

10. Paller AS, Mancini MJ. Photosensitivity and photoreactions. In: Paller AS, Mancini MJ, editors. Hurwitz Clinical Pediatric dermatology. 5th ed. Philadelphia: WB Saunder; 2016:455-458.

11. Kato J, Horimoto K, Sato S, Minowa T, Uhara H. Dermoscopy of melanoma and non-melanoma skin cancers. Front Med. 2019;6:180. doi:10.3389/ fmed.2019.00180

12. Ricotti C, Bouzari N, Agadi A, Cockerell CJ. Malignant skin neoplasms. Med Clinics. 2009;93(6):1241-1264. doi:10.1016/j.mcna.2009.08.011

13. Vempuluru VS, Pattnaik M, Ghose N, Kaliki S. Bilateral ocular surface squamous neoplasia: a study of 25 patients and review of literature. Eur $J$ Ophthalmol. 2021;11206721211007109. doi:10.1177/11206721211007109

14. Tamura D, DiGiovanna JJ, Khan SG, Kraemer KH. Living with xeroderma pigmentosum: comprehensive photoprotection for highly photosensitive patients. Photodermatol Photoimmunol Photomed. 2014;30(2-3):146-152. doi:10.1111/phpp.12108

15. Voiculescu V, Calenic B, Ghita M, et al. From normal skin to squamous cell carcinoma: a quest for novel biomarkers. Dis Markers. 2016;2016:114. doi: $10.1155 / 2016 / 4517492$

Clinical, Cosmetic and Investigational Dermatology

Dovepress

\section{Publish your work in this journal}

Clinical, Cosmetic and Investigational Dermatology is an international, peer-reviewed, open access, online journal that focuses on the latest clinical and experimental research in all aspects of skin disease and cosmetic interventions. This journal is indexed on CAS. The manuscript management system is completely online and includes a very quick and fair peer-review system, which is all easy to use. Visit http://www. dovepress.com/testimonials.php to read real quotes from published authors.

Submit your manuscript here: https://www.dovepress.com/clinical-cosmetic-and-investigational-dermatology-journal 